Pacific Journal of Mathematics

ON THE BERGMAN INTEGRAL OPERATOR FOR AN
ELLIPTIC PARTIAL DFFERENTAL EQUATION WITH A
SNOUT COIFICIENT

NGULAR COEFFIC 


\title{
ON THE BERGMAN INTEGRAL OPERATOR FOR AN ELLIPTIC PARTIAL DIFFERENTIAL EQUATION WITH A SINGULAR COEFFICIENT
}

\author{
P. ROSENTHAL
}

Let $P_{2}(f)$ be Bergman's integral operator of the second kind. In this paper it is shown $(1) P_{2}(f)$ can be uniformly approximated by a linear combination of particular solutions; (2) $P_{2}(f)$ can be analytically continued; (3) $P_{2}(f)$ admits singular points if $f$ is meromorphic.

In the study of functions of one complex variable one derives various relations between properties of the coefficients $a_{\nu}$ of the series development

$$
f(z)=\sum_{\nu=0}^{\infty} a_{\nu} z^{\nu}
$$

of the function $f(z)$ and various properties of $f(z)$ in the large, such as the location and character of the singularities, growth of the function, etc. The method of integral operators enables one to generalize these theorems to the theory of linear partial differential equations

$$
L(\psi)=\frac{\partial^{2} \psi}{\partial z \partial z^{*}}+A_{1}\left(z, z^{*}\right) \psi_{z}+A_{2}\left(z, z^{*}\right) \psi_{z^{*}}+A_{3}\left(z, z^{*}\right) \psi=0 ;
$$

$4\left(\hat{\partial}^{2} \psi \backslash \partial z \partial z^{*}\right)=\Delta_{1} \psi=\left(\partial^{2} \psi \backslash \partial \lambda^{2}+\hat{o}^{2} \psi \backslash \partial \theta^{2}\right), \quad z, z^{*}$ are complex variables, $\lambda=z+z^{*} \backslash 2, \theta=z-z^{*} \mid 2 i, A_{\nu}\left(z, z^{*}\right), \nu=1,2,3$, are regular functions of $z$ and $z^{*}$ in a sufficiently large domain. The situation changes in the case when the $A_{\nu}$ admit singularities. In this paper we consider the equation

$$
L(\psi)=\Delta_{1} \psi+4 F(\lambda) \psi \equiv 0,
$$

where $F(s)=s^{-3}\left(a_{0}+a_{1} s+a_{2} s^{2}+\cdots+a_{n} s^{n}+\cdots\right), s=(-\lambda)^{2 / 3}, a_{0}=5 \backslash 144$, $a_{1}=0$, while the $a_{n}, n \geqq 2$ are such that $\overline{\lim }_{n \rightarrow \infty}\left|a_{n}\right|^{1 / n}=0$.

The integral operator

$$
\psi\left(z, z^{*}\right) \equiv P_{2}(f)=\int_{l} E\left(z, z^{*}, t\right) f\left(\frac{z}{2}\left(1-t^{2}\right)\right) \frac{d t}{\sqrt{1-t^{2}}}
$$

(where $l$ is some rectifiable Jordan path in the upper complex $t$-plane connecting the points -1 and 1 ), transforming analytic functions $f(z)$ in the neighborhood of the origin into solutions of (3), has been introduced and investigated by $\mathrm{S}$. Bergman in $[1,2,5,6]$, see also 
[8], [10]. $E, \not \equiv 0$, called a generating function, is analytic in the three variables $z, z^{*}$ and $t$ providing $\left|z+z^{*}\right|<\left|t^{2} z\right|$.

In analogy to (1) we write

$$
\psi\left(z, z^{*}\right)=\sum_{\nu=0}^{\infty} a_{\nu} \psi_{\nu}\left(z, z^{*}\right)
$$

where

$$
\psi_{\nu}\left(z, z^{*}\right)=\int_{l} E\left(z, z^{*}, t\right)\left(\frac{z}{2}\left(1-t^{2}\right)\right)^{\nu} \frac{d t}{\sqrt{1-t^{2}}} .
$$

In $\S 2$ it is shown every solution $\psi$ regular in the wedge domain $W=\left\{(\lambda, y)\left|3^{1 / 2}\right| \lambda \mid<y, \lambda \leqq 0, y>0\right\}$ (a case which arises in the study of two-dimensional nonviscous compressible fluid flow problems) can be uniformly approximated by finite linear combinations $\sum_{y=0}^{N} a_{\nu} \psi_{\nu}\left(z, z^{*}\right)$, where $z=\lambda+i y, z^{*}=\bar{z}=\lambda-i y$, on certain compact sets $Q \subset W$.

In $\S 3$ an extension and summation method is applied to derive an extension of the operator $\psi$ defined by (5). In $\S 4$ it is shown that the Borel theorem on the multiplication of poles can be extended to $(5)$.

2. Uniform approximation of a solution $\psi$ by finite linear combinations of the particular solutions (6) in $W$. Consider any domain $D \subset W$ which is bounded by the closed segments $0 A_{1}, 0 A_{2}, 0$ the origin, and the arc $\widehat{A_{1} A_{2}}, 0 A_{1}, 0 A_{2}$ lie on the respective lines $\alpha=$ $\alpha_{1}, \alpha_{2}, \pi-\tan ^{-1} \sqrt{3} \geqq \alpha_{1}>\alpha_{2} \geqq \pi \backslash 2$. Let $W \supset R=\{(\lambda, y) \mid y \backslash-\lambda>$ $\left.\left[\left(\left(1-t_{1}^{4}\right)^{1 / 2}\right) \backslash t_{1}^{2}\right], 0<2 t_{1}^{2}<t_{0}^{2}, 0<t_{0}<1,0<t_{0} \leqq|t|, t \in l\right\}, l$ will be specified in what follows. Let $Q$ be compact and $\subset R$.

Theorem. Suppose that $f$ is continuous on $\bar{D}$, closure of $D$, and analytic in $D$ as well as on the boundary segments $0 A_{1}, 0 A_{2}$ including the end points. Then the function

$$
\psi\left(z, z^{*}\right)=\int_{l} E\left(z, z^{*}, t\right) f\left(\frac{1}{2} z\left(1-t^{2}\right)\right) \frac{d t}{\sqrt{1-t^{2}}} \quad z^{*}=\bar{z},
$$

can be uniformly approximated in $Q$ by finite linear combinations of the particular solutions defined in (6).

Proof. We choose for the integration curve $l \equiv C=C_{1} \cup C_{2} \cup C_{3}$, $C_{1}=\left(-1 \leqq t<t_{0}\right), C_{3}=\left(t_{0}<t \leqq 1\right), C_{2}=\left(t=t_{0} e^{i \varphi}, \pi \geqq \varphi \geqq 0,1>t_{0}>0\right)$. The existence of $C$ for our case follows by modifying the proof of Lemma 7.1 of [4], namely, by replacing the inequality $\theta \backslash \Delta>1-t_{1}^{2} \mid t_{1}^{2}$ by $y \backslash-\lambda>\left(1-t_{1}^{4}\right)^{1 / 2} \mid t_{1}^{2}$, substituting $y$ for $\theta$ and $\lambda$ for $\Delta$. This also determines $R$. Our hypotheses about $f$ permit us to rotate the sides 
of the domain $D$ through a small angle $\pi \mid 2>\Delta \alpha>0$ to obtain a wedge-shaped domain $S$ such that $\bar{D} \subset \bar{S}$ and $\bar{S}$ is contained in the domain of regularity of $f$.

Lemma. There exists a $1>t_{0}(\Delta \alpha)>0$ such that if $z \in \bar{D}, t \in C$, then $z\left(1-t^{2}\right) \backslash 2 \in \bar{S}$.

Proof. For $t \in C_{1} \cup C_{3}, 1-t^{2}<1$. Hence $z\left(1-t^{2}\right) \backslash 2 \in \bar{D} \subset \bar{S}$. We next consider the case $t \in C_{2}$. We choose for $t_{0}=\left(\tan ^{2} \Delta \alpha / 1+\tan ^{2} \Delta \alpha\right)^{1 / 4}$. This choice of $t_{0}$ gives then $\Delta \alpha$ for the maximum argument of $1-t^{2}$. Since the maximum of $\left|1-t^{2}\right|=1+t_{0}^{2}$, the lemma follows. Since the domain $W$ was obtained by taking $l$ to be the semi-circle path in the upper half of the $t$-plane, $\psi\left(z, z^{*}\right)$ for $l=C$ is the regular restriction of $\psi\left(z, z^{*}\right)$ for $l=\left(t, t=e^{i \theta}, 0 \leqq \theta \leqq \pi\right)$. This is a known property of the operator defined by (4).

By our assumptions on $f(q)$, we can uniformly approximate $f$ by polynomials $P_{N}(q)=\sum_{n=0}^{N} a_{\nu} q^{\nu}, q \in \bar{S}$, see $[12$, p. 36]. Let $q=$ $1 \mid 2\left(z\left(1-t^{2}\right)\right)$, where $z \in Q, t \in l \equiv C$. By the above lemma, $q \in \bar{S}$. Then

$$
\begin{aligned}
& \mid \int_{l=C} E(z, \bar{z}, t) f\left(\frac{z}{2}\left(1-t^{2}\right)\right) \frac{d t}{\sqrt{1-t^{2}}} \\
& \quad-\int_{l=C} E(z, \bar{z}, t) P_{N}\left(\frac{1}{2} z\left(1-t^{2}\right)\right) \frac{d t}{\sqrt{1-t^{2}}} \mid<\varepsilon L M,
\end{aligned}
$$

$L$ is the length of $C, M=\max _{z \in Q, t \in C}|E(z, \bar{z}, t)|, \varepsilon>0$, and arbitrary. This completes the proof of the theorem.

3. Summation and extension methods applied to the operator $P_{2}(f)$. In the case of analytic functions of one complex variable when considering the series development $f(q)=\sum_{n=0}^{\infty} a_{n} q^{n}$ converging in the star domain, one can determine the values of $f$ in a larger domain using various summation methods.

THEOREM. Consider a sequence of particular solutions $\left(\psi_{\nu}\left(z, z^{*}\right)\right)$. Let $f(q)=\sum_{n=0}^{\infty} a_{n} q^{n}$ in some neighborhood of the origin. Let $\psi\left(z, z^{*}\right)=$ $\sum_{n=0}^{\infty} a_{n} \psi_{n}\left(z, z^{*}\right)$ be the solution determined by $f(q)$ (see (6)). Suppose further that a sequence $\left(\sigma_{n}(\delta)\right)$ is given such that

(1) $\sigma_{n}(\delta)$ is real for $\delta>0$

(2) $\lim _{\tilde{\delta} \rightarrow 0^{+}} \sigma_{n}(\delta)=1$

(3) $\varlimsup_{n \rightarrow \infty}\left|\sigma_{n}(\delta)\right|^{1 / n}=0, \delta>0$

(4) $\varphi_{\delta}(z)=\sum_{n=0}^{\infty} \sigma_{n}(\delta) z^{n} \rightarrow 1 \backslash 1-z$ as $\delta \rightarrow 0^{+}$

uniformly in $z$ in any compact set containing no point of the line $(1, \infty)$. Then $\lim _{\delta \rightarrow 0^{+}} \sum_{n=0}^{\infty} \sigma_{n}(\delta) a_{n} \psi_{n}\left(z, z^{*}\right)$ will give the value of $\psi\left(z, z^{*}\right)$ 
at any point $\left(z, z^{*}\right)$, where $\psi$ exists.

Proof. Let

$$
\psi\left(z, z^{*}\right)=\int_{l} E\left(z, z^{*}, t\right) f\left(\frac{z}{2}\left(1-t^{2}\right)\right) \frac{d t}{\sqrt{1-t^{2}}},
$$

where $f\left(z / 2\left(1-t^{2}\right)\right)$ is the analytic function given at the origin by the series development $f(q)=\sum_{n=0}^{\infty} a_{n} q^{n}$. Since our hypotheses satisfy the known summation theorem, see [9, pp. 190-191], we conclude $\sum_{n=0}^{\infty} \sigma_{n}(\delta) a_{n} q^{n} \rightarrow f(q)$ as $\delta \rightarrow 0^{+}$uniformly in $q$ in every star domain with respect to the origin in which $f(q)$ is analytic. Because of the uniform convergence we are permitted to interchange the order of summation and integration to obtain

$$
\int_{l} E\left(z, z^{*}, t\right) \sum_{n=0}^{\infty} \sigma_{n}\left(\delta, a_{n}\left(\frac{z}{2}\left(1-t^{2}\right)\right)^{n} \frac{d t}{\sqrt{1-t^{2}}}=\sum_{n=0}^{\infty} \sigma_{n}(\delta) a_{n} \psi_{n}\left(z, z^{*}\right) .\right.
$$

Also by our hypotheses we are permitted to interchange the limit and integration operations to obtain,

$$
\lim _{\delta \rightarrow 0^{+}} \int_{l} E\left(z, z^{*}, t\right) \sum_{n=0}^{\infty} \sigma_{n}(\delta) a_{n}\left(\frac{1}{2} z\left(1-t^{2}\right)\right)^{n} \frac{d t}{\sqrt{1-t^{2}}}=\psi\left(z, z^{*}\right) .
$$

(8) and (9) give us the result as was to be shown.

4. Application of a theorem of Borel. Bergman's theory of integral operators enables one to apply results in the theory of functions of one complex variable about the relations between coefficients of $a_{\nu}$ of the development $f(z)=\sum_{n=0}^{\infty} a_{n} z^{n}$ and location and properties of singularities of $f(z)$ to the case of solutions of $L(\psi)=0$. That singularities can occur for the operator $P_{2}(f)$, we note the following, which is an immediate consequence of a result in [5]: Let the associate function $f(q)$ be meromorphic with poles at $q=q_{i} \neq 0,1 \leqq i \leqq k$. Then $\psi\left(z, z^{*}\right)=P_{2}(f)$ will be singular, i.e., will not admit a Taylor series about the points $\left(z, z^{*}\right), z^{*}=-z, z=2 q_{1}, \cdots, 2 q_{k}$.

THEOREM. Assume that $\psi\left(z, z^{*}\right)$ has the development $\sum_{n=0}^{\infty} a_{n} b_{n} \psi_{n}(z$, $\left.z^{*}\right)$, where $a_{n}, b_{n}$ are the coefficients respectively of the meromorphic functions $a(q), b(q)$ with series development about the origin $\sum_{n=0}^{\infty} a_{n} q^{n}$, $\sum_{n=0}^{\infty} b_{n} q^{n}$, and poles at $\alpha_{i}, i=1, \cdots, p, \beta_{k}, k=1, \cdots, r$, respectively. Then $\psi\left(z, z^{*}\right)$ is singular at the points $z^{*}=-z=-2 \alpha \beta_{k}$, providing $\alpha_{i} \beta_{k} \neq \alpha \beta$, where $\alpha, \beta$ are any other singular points or external points of $a(q)$ and $b(q)$.

Proof. By a theorem of Borel (see $[7$, p. 106]) the function 
$f(q)=\sum_{n=0}^{\infty} a_{n} b_{n} q^{n}$ has poles at the points $\alpha_{i} \beta_{k}$. By the result mentioned in $\S 4$ the theorem follows.

\section{REFERENCES}

1. S. Bergman, Two-dimensional transonic flow patterns, Amer. J. Math. 70 (1948), 856-891.

2. - On solutions of linear partial differential equations of mixed type, Amer.

J. Math. 74 (1952), 444-474.

3. - Integral operators in the theory of linear partial differential equations, Springer-Verlag, Band 23, Second Revised Printing, 1969.

4. - On an initial value problem in the theory of two-dimensional transonic flow patterns, Pacific J. Math. 32 (1970), 29-46.

5. - A representation of solution of a class of equations of mixed type (to appear)

6. S. Bergman and R. Bojanic, Application of integral operators to the theory of partial differential equations with singular coefficients, Arch. Rational Mech. Anal. 4 (1962), 323-340.

7. L. Bieberbach, Analytische Fortsetzung, Springer Verlag, Heft 3, 1955.

8. R. P. Gilbert, Function Theoretic Methods in Partial Differential Equations, Academic Press, 1969.

9. G. Hardy, Divergrent series, Oxford University Press, 1967.

10. Abhyankar-Risk, Analytic methods in mathematical physics (Conf. Proceedings), Gordon and Breach, 1970.

11. I. N. Vekua, New Methods for Solving Elliptic Equations, Wiley, 1967.

12. J. Walsh, Interpolation and Approximation by Rational Functions in the Complex Domain, Amer. Math. Soc. Coll. Pub., Vol. 20, 4th Ed., 1965.

Received November 12, 1969. This investigation was supported in part by contract AEC, AT 04-3-326 PA-22.

STANFORD UNIVERSITY 



\section{PACIFIC JOURNAL OF MATHEMATICS}

\section{EDITORS}

\author{
H. SAMELSON \\ Stanford University \\ Stanford, California 94305

\section{Richard Pierce} \\ University of Washington \\ Seattle, Washington 98105
}

J. DugundJI

Department of Mathematics

University of Southern California

Los Angeles, California 90007

RichaRd ARENS

University of California

Los Angeles, California 90024

\section{ASSOCIATE EDITORS}
E. F. BECKENBACH
B. H. NeUMANN
F. WOLE
K. YoshidA

\section{SUPPORTING INSTITUTIONS}

\author{
UNIVERSITY OF BRITISH COLUMBIA \\ CALIFORNIA INSTITUTE OF TECHNOLOGY \\ UNIVERSITY OF CALIFORNIA \\ MONTANA STATE UNIVERSITY \\ UNIVERSITY OF NEVADA \\ NEW MEXICO STATE UNIVERSITY \\ OREGON STATE UNIVERSITY \\ UNIVERSITY OF OREGON \\ OSAKA UNIVERSITY \\ UNIVERSITY OF SOUTHERN CALIFORNIA
}

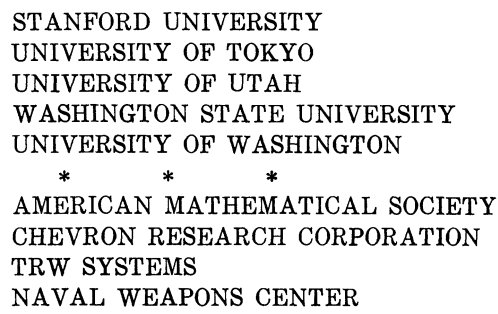

The Supporting Institutions listed above contribute to the cost of publication of this Journal, but they are not owners or publishers and have no responsibility for its content or policies.

Mathematical papers intended for publication in the Pacific Journal of Mathematics should be in typed form or offset-reproduced, (not dittoed), double spaced with large margins. Underline Greek letters in red, German in green, and script in blue. The first paragraph or two must be capable of being used separately as a synopsis of the entire paper. The editorial "we" must not be used in the synopsis, and items of the bibliography should not be cited there unless absolutely necessary, in which case they must be identified by author and Journal, rather than by item number. Manuscripts, in duplicate if possible, may be sent to any one of the four editors. Please classify according to the scheme of Math. Rev. Index to Vol. 39. All other communications to the editors should be addressed to the managing editor, Richard Arens, University of California, Los Angeles, California, 90024.

50 reprints are provided free for each article; additional copies may be obtained at cost in multiples of 50 .

The Pacific Journal of Mathematics is published monthly. Effective with Volume 16 the price per volume (3 numbers) is $\$ 8.00$; single issues, $\$ 3.00$. Special price for current issues to individual faculty members of supporting institutions and to individual members of the American Mathematical Society: $\$ 4.00$ per volume; single issues $\$ 1.50$. Back numbers are available.

Subscriptions, orders for back numbers, and changes of address should be sent to Pacific Journal of Mathematics, 103 Highland Boulevard, Berkeley, California, 94708.

PUBLISHED BY PACIFIC JOURNAL OF MATHEMATICS, A NON-PROFIT CORPORATION

Printed at Kokusai Bunken Insatsusha (International Academic Printing Co., Ltd.), 7-17, Fuj̣imi 2-chome, Chiyoda-ku, Tokyo, Japan. 


\section{Pacific Journal of Mathematics}

\section{Vol. 35, No. $2 \quad$ October, 1970}

Valentin Danilovich Belousov and Palaniappan L. Kannappan, Generalized Bol functional equation .................................... 259

Charles Morgan Biles, Gelfand and Wallman-type compactifications ........... 267

Louis Harvey Blake, A generalization of martingales and two consequent convergence theorems .................................... 279

Dennis K. Burke, On p-spaces and $w \Delta$-spaces..................... 285

John Ben Butler, Jr., Almost smooth perturbations of self-adjoint operators . . . . . . 297

Michael James Cambern, Isomorphisms of $C_{0}(Y)$ onto $C(X) \ldots \ldots \ldots \ldots \ldots . \ldots 307$

David Edwin Cook, A conditionally compact point set with noncompact closure ... 313

Timothy Edwin Cramer, Countable Boolean algebras as subalgebras and homomorphs .........................................

John R. Edwards and Stanley G. Wayment, A v-integral representation for linear operators on spaces of continuous functions with values in topological vector spaces.............................................

Mary Rodriguez Embry, Similarities involving normal operators on Hilbert

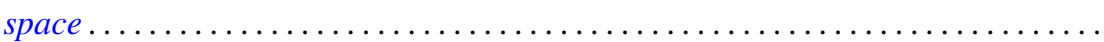

Lynn Harry Erbe, Oscillation theorems for second order linear differential

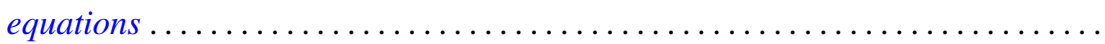

William James Firey, Local behaviour of area functions of convex bodies .......... Joe Wayne Fisher, The primary decomposition theory for modules ..............

Gerald Seymour Garfinkel, Generic splitting algebras for Pic ..................

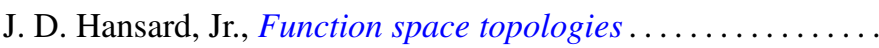

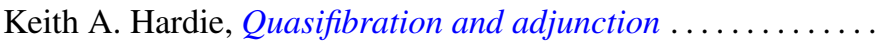

G. Hochschild, Coverings of pro-affine algebraic groups ...........

Gerald L. Itzkowitz, On nets of contractive maps in uniform spaces ..

381

389

399

417

Melven Robert Krom and Myren Laurance Krom, Groups with free nonabelian subgroups....................................

James Robert Kuttler, Upper and lower bounds for eigenvalues by finite differences ......................................

Dany Leviatan, A new approach to representation theory for convolution transforms . . .

Richard Beech Mansfield, Perfect subsets of definable sets of real numbers ...

Brenda MacGibbon, A necessary and sufficient condition for the embedding of a

Lindelof space in a Hausdorff $\mathscr{H} \sigma$ space ..................

David G. Mead and B. D. McLemore, Ritt's question on the Wronskian ....

Edward Yoshio Mikami, Focal points in a control problem .....

Paul G. Miller, Characterizing the distributions of three independent n-dimensional random variables, $X_{1}, X_{2}, X_{3}$, having analytic characteristic functions by the joint distribution of $\left(X_{1}+X_{3}, X_{2}+X_{3}\right)$. . .

P. Rosenthal, On the Bergman integral operator for an elliptic partial differential equation with a singular coefficient....

Douglas B. Smith, On the number of finitely generated $O$-group 